\section{ENZYME INHIBITORS}

\section{Enzyme and Metabolic Inhibitors}

By J. Leyden Webb. Vol. 2: Malonate, Analogs, Dehydroacetate, Sulfhydryl, 0-Iodosobenzoate, Mercurials. Pp. $\mathrm{xx}+1237$. 272s. Vol. 3: Iodoacetate, Maleate. $N$-Ethylmaleimide, Alloxan, Quinones, Arsenicals. Pp. xx +1028. 256s. (New York: Academic Press, Inc.; London: Academic Press, Inc. (London), Ltd., 1966.)

THE subject of this book is an analysis of action of selected enzyme inhibitors in terms of the physiochemical mechanisms of their effect on isolated enzymes and the metabolic consequences of enzyme inhibition on more integrated cellular functions. The effects on animal, microbial and plant cells are discussed without discrimination between species.

Volume 2 contains four chapters-on malonate, analogues of enzyme reaction components, dehydroacetate and sulphydryl reagents respectively. Volume 3 has seven chapters, on iodoacetate and iodoacetamide, maleate, $N$-ethylmaleimide, alloxan, quinones, arsenicals, and comparison of sulphydryl reagents.

Although the author deserves considerable credit for collecting large amounts of material, it is difficult to avoid directing attention to significant shortcomings. The most general is an apparent weakness of logical structure, leaving the impression of a more or less random collection of information which has not been sorted out authoritatively. It is almost unrealistic to expect authoritative knowledge from a single author in as many diverse fields as are dealt with in this work. It would have been less risky to have left many unsolved problems in the form of accurate descriptions of phenomena without attempts at interpretation. The penalty for the author's encyclopaedic ambitions is an unbalanced presentation of both excellent and unreliable references, some inaccuracies of quotation, and occasionally interjections of unfounded subjective opinions. Perhaps the most creditable aspect of the contents of the two volumes is a tendency to emphasize physicochemical considerations. It is unfortunate, however, that important advances in the field of enzymatic mechanisms, particularly relationships of protein structure to catalytic activity, have been virtually ignored. It is equally disappointing that significant advances in molecular biology which provide interesting examples of mechanisms of action of inhibitors are not to be found in these volumes.

A few examples illustrate these shortcomings and may serve as a warning to the reader. On page 44 , Volume 2 , we find the remarkable conclusion that the active site of succinic dehydrogenase has a "slit or tubular" structure, a statement which, in the absence of more serious physical information, is no comfort to enzyme or protein chemists. Effects on isolated enzymes and on enzyme systems (for example, electron transfer systems) are sometimes confused (that of the calcium ion, for example, on page 47). It is unfortunate that some well-known biochemical mechanisms appear to be terra incognita if one wishes to depend on this text for information (including uncoupling of oxidative phosphorylation, Crabtree and Pasteur effects, pages 115, 119, 127; interpretation of lipid metabolism, page 137; omission of participation of carbamyl phosphate in the urea cycle, page 157 , etc.). The chaotic method of presenting diverse subjects ranging from inhibitors of fumarase to vitamin analogues is especially evident in Chapter 2 of Volume 2. There are some misquotations of published papers (for example, on page 334), and also noticeable omissions, faults which introduce uncertainty in the text. Although Chapters 5 and 6 of Volume 3 are more carefully organized, they tend to be repetitious.

These volumes will remain sources of varied information without the assurances of accuracy, reliability and up to date interpretation which one expects from an authoritative handbook.
Polarography 1964

Edited by Graham J. Hills. (Proceedings of the Third International Congress, Southampton.) Vol. I : Pp xvi + 1-686 + xvii-xxviii. Vol. 2: Pp. xv+687-1164+ xvii-xxviii. (London: Macmillan and Co., Ltd., 1966.) $315 s$. the set.

IT is sometimes difficult for those actively engaged in electro-analytical chemistry - and impossible for those not so engaged - to appreciate the wide interest in, and the possibilities of, the technique simply described as polarography. Only by perusal of volumes like these does there come a realization of the tremendous impact that polarography has made and continues to make on electrochemistry.

'These volumes are a record of the 1964 International Congress of Polarography organized by the Polarographic Society and held at the University of Southampton. The record consists of eighty-nine papers. Among them are reviews such as that by Kolthoff of the fundamentals of polarography in inert solvents; recent trends in organic polarography by Zuman; recent developments in direct current polarography and recent advances in highresistance polarography. For the specialist there is a range of papers covering as wide a selection as the polarography of oxidized and reduced forms of diphosphopyridine nucleotide to the kinetics of fast reactions. Fully to appreciate the possibilities, it will be necessary to purchase both volumes, but those who do so will find them worth while.

R. J. MAGEE

\section{The Fundamentals of Mathematical Analysis}

Vol. 1. By G. M. Fikhtengol'ts. Translation edited by Ian N. Sneddon. (International Series of Monographs in Pure and Applied Mathematics, Vol. 72.) Pp. xxvi+494. (London and New York: Pergamon Press, Ltd., 1965.) $50 s$. net.

THIs book was originally published in Russian in 1960 and consists of the usual development of analysis at the university level. It starts with the Dedekind definition of irrationals, and uses the concept of variables in discussing the idea of function. Limits are introduced using infinitesimals (null sequences), and the normal development through continuity, differentiability to the Riemann integral and functions of several variables follows. There are applications of the theory to problems of maxima and minima, length of a curve, indeterminate forms and areas and volumes. It concludes with a historical survey of the early works in differential calculus. The main defect from the student's point of view is that there are no exercises, though there are several worked examples.

R. L. PerRy

The Fundamentals of Mathematical Analysis

Vol. 2. By G. M. Fikhtengol'ts. Translated by Ann Swinfen. Translation edited by Ian N. Sneddon. (International Series of Monographs in Pure and Applied Mathematics, Vol. 73.) Pp. xxi +518 . (London and New York: Pergamon Press, Ltd., 1965.) 55s, net.

IN this volume, G. M. Fikhtengol'ts continues the development of analysis through the usual university syllabus. A discussion on the convergence of series is followed by a considerable section on uniform convergence and the interchange properties associated with it. A continuous, nowhere differentiable function is constructed. The text continues with the theory of implicit functions, multiple integrals and Fourier series and integral. Interspersed with the development of the theory are sections on the historical background. Tho book concludes with a brief introduction to the further developments of analysis. It is a satisfactory, if somewhat lengthy text, covering a little more than is usually included in a specialist pure mathematical course in analysis, though there is no theory of sets or mention of enumerability. Together the volumes contain more than 1,000 pages.

R. L. Perry 